\section{2}

\title{
Optimization of Tugboat Propulsion System Configurations: A Holistic Life Cycle Assessment Case Study
}

Haibin Wang*1, Peilin Zhou ${ }^{1,2}$, Yibo Liang ${ }^{1}$, Byongug Jeong ${ }^{1}$, Ana Mesbahi ${ }^{1}$

1- Department of Naval Architecture, Ocean and Marine Engineering, University of Strathclyde, 100 Montrose Street, Glasgow, G4 0LZ, UK

2- Harbin Institute of Technology, Weihai; No.2, West Wenhua Road, Weihai, Shandong, 264209, China

Contact number: $+44(0) 7419704603$

Email: haibin.wang.100@strath.ac.uk

\begin{abstract}
The International Maritime Organization has initialized a strategy to reduce $30 \%$ and $50 \%$ of carbon dioxide emissions from marine activities by 2030 and 2050 respectively. It is extremely challenging to achieve but innovative cleaner technologies are under research and development to help control and reduce maritime carbon emission. One fact is that the usage of tugboats has been increasing in recent years as huge demands of marine offshore activities (construction, installation and maintenance of renewable islands and wind farms); therefore, the performance of tugboats should be well-evaluated which could be a valuable contribution to maritime emission reduction. This paper focuses on investigating a tugboat's life cycle performance, specifically comparing different configurations of the propulsion system and selecting an optimal system with the lowest emissions release, costs and hazard impacts. A case study was carried out comparing five different engine configurations with the help of commercial and inhouse developed life cycle assessment software in order to comprehensively evaluate the ship performance. Three main life phases, three evaluation flows, four emission categories and three criteria, were under consideration in this study. The results indicate LCA method and the inhouse software could help to compare and determine optimal configurations and the engine configuration with three medium size engines is the optimal one which generated lowest emissions equivalent to 15.5 million euros, invested 14.2 million euros and occur a risk impact equivalent to 1.01 million euros. This paper not only provides a case study for the tugboat configuration assessment but also recommends LCA methodology as a general evaluation method for emission reduction technologies who have to meet the extreme requirements of emission control in the next few decades.
\end{abstract}

\section{KEYWORDS:}

Emissions control; Life Cycle Assessment; tugboat performance; propulsion system configuration. 


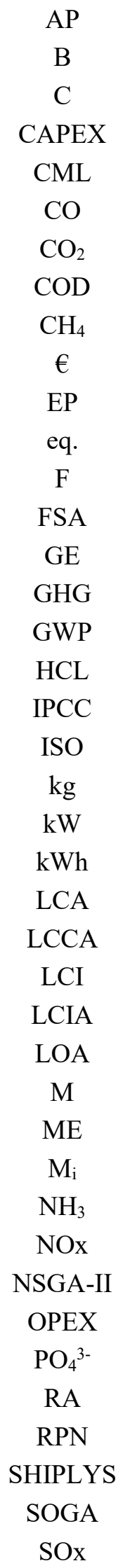

$$
\begin{gathered}
\text { Acidification potential } \\
\text { Breadth } \\
\text { Consequence } \\
\text { Capital expenditure }
\end{gathered}
$$

Institute of Environmental Sciences

Carbon monoxide

Carbon dioxide

Chemical oxygen demand

Methane

Euro

Eutrophication potential

Equivalent

Frequency

Formal Safety Assessment

Generator engine

Greenhouse gases

Global warming potential

Hydrochloric acid

Intergovernmental Panel on Climate Change

International Organization for Standardization

kilogram

kilo-watt

kilo-watt hour

Life cycle assessment

Life cycle cost assessment

Life cycle inventory

Life cycle impact analysis

Length overall

Mitigation

Main engines

$\mathrm{i}^{\text {th }}$ machinery

Ammonia

Nitrogen oxides emission

Non-dominated sorting genetic algorithm II

Operational expenditure

Phosphate

Risk assessment

Risk priority number

Ship Life Cycle Software Solutions

Single-objective genetic algorithm

Sulphur oxides emission 


\section{INTRODUCTION}

39 For quite some time, environemtal protection has attracted the attention of researchers and 40 scientist due to the severity of environmental impacts that have greatly increased in recent 41 years. One of the impact is the global warming effect which is mainly caused by $\mathrm{CO}_{2}$ from the consumption of fossil fuels. In addition to $\mathrm{CO}_{2}$, acid gases has drawn the attention from scientists, such as $\mathrm{SO}_{\mathrm{x}}$ and $\mathrm{NO}_{\mathrm{x}}$ which will lead to acid rains after released into the atmosphere. All these pollutions are a result of burning fossil fuels; therefore, the control and reduction of emissions from human activities is one of the most interesting topics all over the world.

Emissions from international shipping is expected to grow between $50 \%$ and $250 \%$ by 2050 due to the growth of world maritime activities (Smith et al., 2015). The IMO has set up a goal by 2050 to reduce the total annual greenhouse gases from international shipping by at least $50 \%$ (IMO, 2018a). There are many solutions proposed or tested to meet these demands, such as alternative fuels, hybrid systems and route optimisations. These all are aimed to increase energy efficiency and reduce the emissions generated and released: the selection of alternative fuels with a reduced content of sulphur will generate a smaller amount of $\mathrm{SO}_{\mathrm{x}}$; similaryly, the usage of liquefied natural gas will help reduce emissions too, such as $\mathrm{NO}_{\mathrm{x}}, \mathrm{SO}_{\mathrm{x}}$ and $\mathrm{CO}_{2}$; some researchers intend to apply bio-fuel on board which is able to reduce the carbon emissions as the fuel is generated from the plants who are continuously absorbing $\mathrm{CO}_{2}$ from the atmosphere; the hybrid system is another way to mitigate air pollution, as it combines the use of batteries with the conventional system and the batteries can be re-charged by using renewable energy or power from the power plant (bulk energy provider) whose emission will be much lower than traditional on-board power systems; with the increasing in forecasting technologies and databases, the sea conditions of vessel route (wind, wave, tidal) can be predicted and the optimal route with lowest fuel consumption but an acceptable schedule can be determined. All these technologies have been developed and will help mitigate the current global warming trend and acidification situations. However, there are only a few discussions or research work carried out on the ship propulsion power management from the perspective of emissions control and environmental protection. As a growing offshore activities due to the applications of renewable islands and wind farms, the demands of tugboats are increasing rapidly recently but there are only a few studies on enhancing the tugboat performance. Therefore, this paper will focus on a tugboat power output management to find out the optimal engine configurations and engine output according to the power demand of the vessel. The optimal configurations will enable the engine to be operated under the most effective loads with the lowest fuel consumption and emissions. To expand the analysis and consider the whole life span of a vessel, a life cycle assessment will be carried out to indicate the performance of ship power output management through the vessel's whole service life. With the consideration of ship life span and finding the optimal engine configurations, the emission release from tugboat operation could be quantified and minimized, which will become an indispensable contribution to fulfil the severe emission control requirement of marine industry. 
There are many applications of emission control technologies on marine vessels but only a few of them focused on tugboat. Some research worth mentioning which considered the analysis on tugboats activities and their performances are mentioned in this section. In recent work, Yang has conducted a process-based LCI for the first offshore wind power plant in China (Yang et al., 2018) and the materials and equipment supply of the power plant were mainly relied on barges, tugboats, and deck barges. However, although tugboat transportation is a significant way for offshore applications such as wind farms, there is a few research studies about tugboats: Gökalp applied kerosene fuel blended with aspire methyl ester on a tug boat and carried out exergy analysis on the vessel to determine the environmental impacts of this application (Gökalp, 2018). The results indicated that biofuel could help reduce the CO emissions but as a drawback, the $\mathrm{NO}_{\mathrm{x}}$ emissions will be higher. Overall, the usage of bio-fuels is a good way to reduce the emissions but his study only focuses on the operation phase and as such lacks of the complete view over the life cycle of the vessel. The economic analysis was also not under consideration which means this is not a comprehensive study.

Research has also been conducted (Zhu et al., 2018) on the tug ship equipped with a hybrid system and it considers both the impacts of environment and cost. This was a comparative study in which different optimisation methods were used to determine the optimal operation performance of the hybrid propulsive system (a combination of battery with conventional system) on the tug ship. However, the study shortens the life cycle to construction and operation only and disregards the maintenance and scrapping/dismantling phases of the vessel. The focus of the study was also to prove the excellence of non-dominated sorting genetic algorithm II (NSGA-II) from the single-objective genetic algorithm (SOGA).

Additionally, Zhen's team (Zhen et al., 2018) focused their research on the tug ship but only on its scheduling which was optimised barge assignments of the tugboat to minimise the required tugs. The model established was validated by experiments. This work was also a good start to assess the performance of tugboats operation schedule which is aimed to minimize the number of tug vessels involved as well as to reduce the operational costs and related emissions release.

Therefore, one main purpose of this paper is to investigate the tugboat from a more comprehensive point of view. A large number of research has been performed using life cycle assessment to help the marine industry select optimal solutions: examination of the economicenvironmental effects of two different hull coating methods and three different types of Ballast Water Treatment Systems were carried out from the perspective of life cycle impacts (BlancoDavis et al., 2014; Blanco-Davis and Zhou, 2014); LCA method was applied to a case study 
114 for evaluating the economic-environmental benefits of a hybrid power system on a Ro-Ro

115 vessel (Ling-Chin and Roskilly, 2016a, 2016b) and on marine propulsion systems (Ling-Chin

116 and Roskilly, 2016c); They concluded that LCA was an effective process for proper decision

117 making as it could aid evaluating the holistic impact on the environment, human beings and

118 natural reserves. Another research about application of solar panels on board a short route ferry

119 adopted LCA method, which carried out a performance comparison between the new solar

120 panel application and the original ferry, and indicated the environmental and economic benefits

121 of the application (Wang et al., 2019). Ship retrofitting processes were explored in the LCA

122 aspects by Koch et al. (Koch et al., 2013), specifically focusing on the work load, labour and

123 facility arrangement optimisation in the shipyard. There is also a research study about the steel

124 recycling from ships in Indian shipyard which applied life cycle assessment (Rahman et al.,

125 2016). It covered the evaluation of recycle performance (both energy use and emissions), from

126 transporting from the originating country to dismantling in Chittagong, to the final recyclers in

127 Dhaka. It also discovered most of the environmental damage happened when rerolling the steel.

128 As presented here, recent research focusing on tug vessels gives very good insight into 129 environmental and cost impacts for this type of vessels, but it clearly lacks a full and 130 comprehensive analysis. In Favi's study, they were striving to develop an assessment approach 131 and data framework to evaluate the complex marine vessels based on design information in 132 order to make LCA and LCCA compatible with existing standard (Favi et al., 2018). However, 133 the study was highly depending on the design information and the ship types under 134 considerations are yachts, ferries, cruise ship, merchant ships, fishing vessels and pipe laying 135 vessel. Hence, this paper strives to assess the performance of a tugboat from the perspective of 136 environmental, risk and cost assessment. As the on-board propulsion system configuration is 137 one way to reduce the energy consumption, it will lead to the result in the reduction of 138 emissions from the ship exhaust gas. However, since the lack of evaluation method for marine 139 vessels, their performances are unavoidable underestimated or misevaluated. Life cycle 140 assessment is a comprehensive methodology which considers from the cradle to grave life of a 141 system or product to quantify its impact on the environment. This paper a will apply LCA on 142 tugboat to discover the performances of the selected case study ship and compare different 143 engine configurations to determine an optimal one with most desirable performances from the 144 point view of environmental protection, cost saving and risk reduction.

145 There are several commercially available software packages that can be used for life cycle 146 analysis, but at present none of them is specifically developed for the marine/ship building 147 industry, which leads to time consuming, difficult and incomplete life cycle assessments. This 148 paper will also validate the in-house software developed by comparing the results with those 149 from commercial software. 
151 The section of methodology will both state the processes of life cycle assessment and the related formula which will support the evaluation of a case ship study.

\subsection{Life CyCle Assessment MeTHOD}

The ISO standards indicate that LCA analysis should fundamentally include four processes: the definition of research/analysis objectives and boundaries, Life Cycle Inventory Analysis (LCI), Life Cycle Impact Analysis (LCIA) and life cycle interpretation (ISO, 2006a, 2006b). Figure 1 presents the flowchart and relationships between these processes.

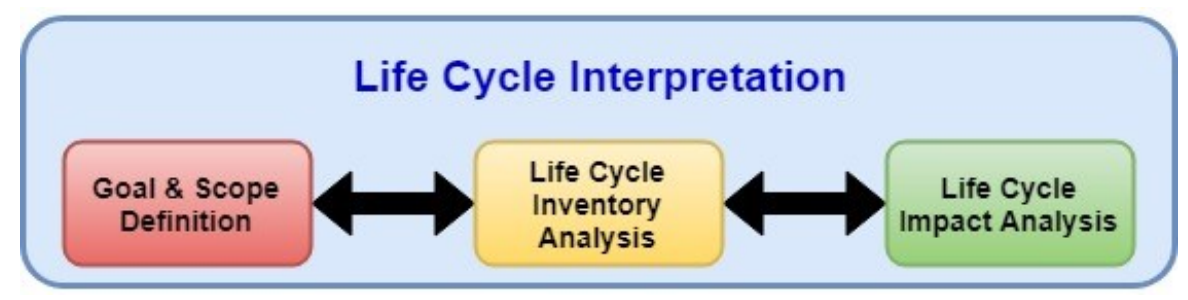

Figure 1 The schematic chart of life cycle assessment

To conduct an LCA analysis, the first step is to define the objectives and boundaries. A typical objective of research study is to determine a specific performance or cost of a system or product and similarly, LCA study is to obtain the environmental impact. There are a huge amount of different environmental impacts that can be considered, for example, Global Warming Potential (GWP), Acidification Potential (AP) and Eutrophication Potential (EP); hence it is essential to set up the purpose of the study and its main targets. The scope and boundaries should also be considered and as the goal is set up, the selection and consideration of certain types of potential (e.g. GWP, AP or EP) should be carried out based on the goal. There will be many emissions and pollutants under evaluation, hence some have been neglected as they have insignificant impacts on the primary goal. After the potentials selected, a functional unit should be set up as a standard to carry out the evaluation and comparisons of different scenarios. A normalisation process will be conducted, which converts considered emissions from different potentials into one indicator (selected pollutant). According to the CML database (CML, 2016), all the emissions that contribute to global warming will be normalized and converted into an equivalent quantity of $\mathrm{CO}_{2}$ and the unit is $\mathrm{kg} \mathrm{CO}_{2}$ equivalent. Similarly, for AP and EP, the fundamental pollutants are sulphur dioxide and phosphate $\left(\mathrm{SO}_{2}\right.$ and $\left.\mathrm{PO}_{4}{ }^{3-}\right)$. Usually, a functional unit could be the quantified ship performance during its service, but they can always be set up by the end-users based on their objective. The normalisation process helps simplify the set up process which usually is based on the normalised units. Definition of the system boundary is an important part as well. Not only constraining the scope by the relevant emissions, but also identifying the differences between alternatives could help limit the LCA 
scope which can be extremely complex, so that a compact but adequate LCA model can be established without considering repeated, redundant and less effective parts of the system or product. Therefore, a reasonable scope should be made in order to neglect these unnecessary parts. Furthermore, assumptions should be made as well in order to progress the analysis as sometimes real data cannot be retrieved or provided. These assumptions should be made or advised by the system or product owners, manufacturers and operators.

After the definition of goal, scope and boundaries, the life cycle inventory analysis can be conducted as shown in the schematic diagram in Figure 2. It starts with the defined goal and scope in the previous step where an initial LCA plan has been selected and determined. With this plan, data involved in the plan can be collected, normalised and aggregated so that initial outcomes could be determined. However, the scope of the LCA analysis will be expanded or reduced based on the availability of relevant data. After adjusting the scope based on data availability, similar processes of data collection, normalisation and aggregation will be conducted so that a modified but complete inventory of an LCA analysis can be obtained.

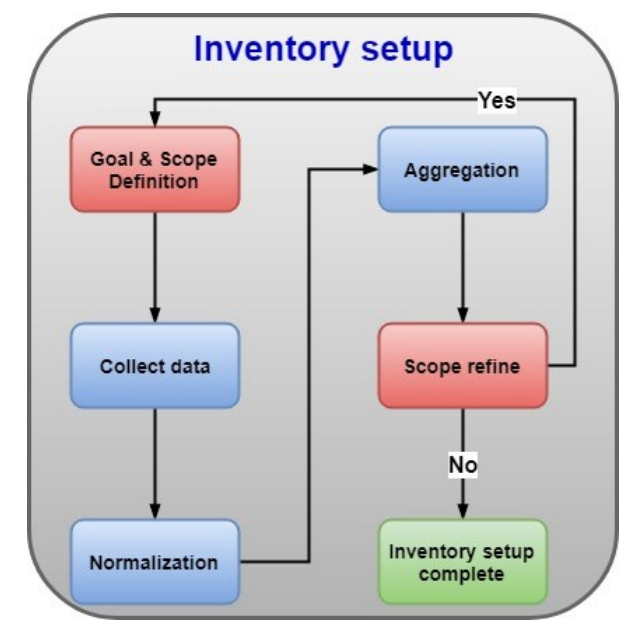

Figure 2 Schematic chart of life cycle inventory analysis

The LCI analysis will be used as a fundamental part of the LCIA which consists of three main steps:

a. Selection: impact categories chosen including indicators and characterization models;

b. Classification: LCI results assigned to the selected impact categories;

c. Characterization: calculation using LCI results as input and characterization models to determine results based on category indicator.

In the last phase, life cycle interpretation, a sensitivity analysis will be carried out to evaluate impacts of the selected inputs on the established LCA processes and results, i.e. mid-term and end-term results. These inputs are selected based on their significance, availability, and uncertainty. 
209 The results will indicate the significant performances based on the LCI and LCIA analysis

210 which usually provide end-users recommendations on the selections of different alternatives.

211 Furthermore, the conclusions, limitations and recommendations of the LCA analysis should be

212 provided in this interpretation processes which illustrate not only the decisions made but also

213 the constraints of the analysis.

\section{3.2. FORMULA GOVERNING}

215 As this paper will mainly focus on the main engine and its related activities, the fuel oil

216 consumption during the operation phase of the vessel is considered and a general equation is

217 used to calculate the fuel oil consumption for these activities Equation (1):

$$
\mathrm{FC}=\sum_{i=1}^{n} \mathrm{Pe}_{\mathrm{i}} \times \mathrm{SFOC}_{i} \times \mathrm{H}_{i} \mathrm{i} \times \mathrm{LS}
$$

219 Where,

$220 \quad \mathrm{FC}$ is the annual fuel consumptions [g];

221 Pe is the power requirement during vessel operation [kW];

222 SFOC is the specific fuel oil consumptions of the engine under specific engine output $[\mathrm{g} / \mathrm{kWh}]$;

$223 \mathrm{H}$ is the number of operation hours in a year [hours];

224 LS is the number of years of the vessel life span [years];

$225 \mathrm{~N}$ is the total number of operation conditions under consideration;

226 i represents the number of different vessel operation conditions under different engine loads.

228 Due to engine load variation under different operating conditions, the SFOC adjustment for the 229 engine will be considered based on the engine project guide data shown in Figure 3. Equation 230 (2) gives the interpolation curve of this figure (Dedes, 2013):

$$
\mathrm{SFOC}=378.8-387.2 \times \mathrm{EL}^{3}+880.2 \times \mathrm{EL}^{2}-657.3 \times \mathrm{EL}
$$

$$
\mathrm{Q}_{\mathrm{NOx}}=8.56-9.392 \times \mathrm{EL}^{3}+8.522 \times \mathrm{EL}^{2}+4.235 \times \mathrm{EL}
$$

Where,

234 SFOC is the specific fuel consumption under a certain engine load [ $\mathrm{g} / \mathrm{kWh}$;

$235 \mathrm{Q}_{\mathrm{NOx}}$ is the specific $\mathrm{NO}_{\mathrm{x}}$ emission under a certain engine load $[\mathrm{g} / \mathrm{kWh}$; 


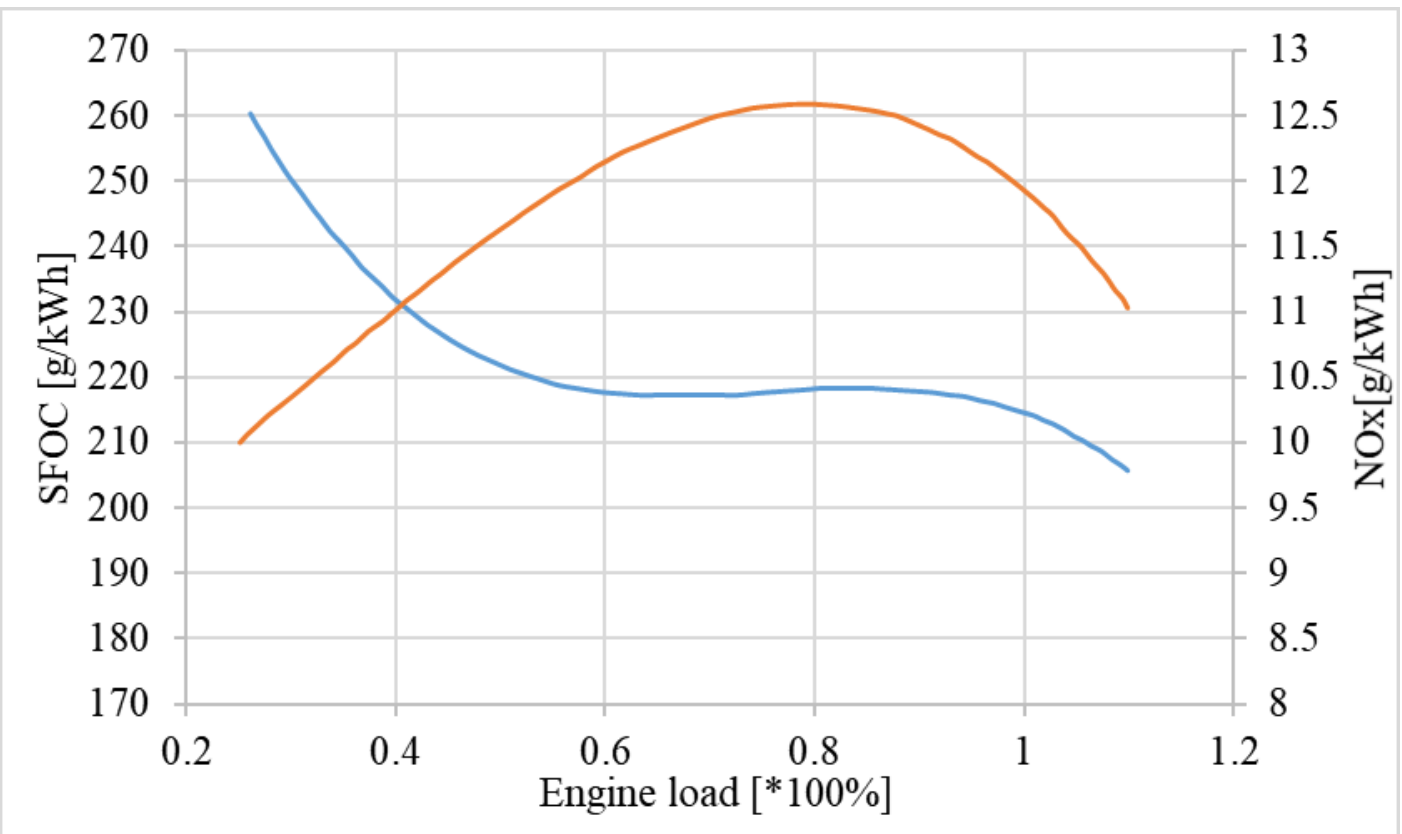

Figure 3 Typical SFOC curves and $\mathrm{NO}_{\mathrm{x}}$ emission curves for diesel generators

241 Emissions can be theoretically estimated based on emission factors and fuel consumption in 242 Equation (3):

$$
\mathrm{Q}_{\mathrm{e}}=\mathrm{C}_{\mathrm{f}} \times \mathrm{FC}
$$

244 Where,

$245 \mathrm{Q}_{\mathrm{e}}$ is the quantity of emission from engine operation $[\mathrm{g}]$;

$246 \mathrm{C}_{\mathrm{f}}$ is the emission factors of fuel burnt in the engine $[\mathrm{g} / \mathrm{g}]$;

$247 \quad \mathrm{FC}$ is the annual fuel consumptions [g].

\section{LCA ANALYSIS AND DISCUSSION}

The LCA analysis will be performed following the methodology described in Section 3, starting from the aim and scope definition, followed by a life cycle inventory setup and impact assessment.

\subsection{AIM AND SCOPE}

The aim of this research has been stated in the introduction and it is to explore the impact of different engine configurations on a tugboat taking into account fuel savings and emission reduction performance. The details for the case study ship selected for this purpose are shown in Table 1 and Table 2.

258 The research focuses on the engine configuration and the following assumptions are made before carrying out the analysis: 
a. Only the main engines and their related activities are involved (Figure 4): engine installation (purchase, transportation and installation), operation (fuel production, transportation and consumption) and scrapping (transportation, cutting and recycling);

b. Carbon emissions from engine fuel consumption are calculated based on emission

The maintenance phase is a significant focus as the numbers, hours and loads of engine operation are varied greatly. Therefore the maintenance activities (emission and cost) will give a new angle to investigate the optimal alternatives.

280 In this case, the maintenance phase is considered as out of scope and will be investigated in the future. It is because the software could estimate the engine running hour related maintenance cost, but the database is based on a short route ferry and may not be compatible with tug vessel. Also, the focus of tug vessel maintenance will be different from ferry because tug vessel operates in different sea states, but ferry operates between two destinations. However, if historical data is ready, the estimation of maintenance cost for tug vessel will be completed.

286 In the next section, the LCA model for this ship is established and presented which will be used as a benchmark in the life cycle impact analysis.

Table 1 Case study vessel information

\begin{tabular}{|c|c|c|}
\hline \multicolumn{2}{|c|}{ Vessel specification } \\
\hline Name & \multicolumn{2}{|c|}{ Salvation 21 } \\
\hline Flag & 32.3 & meter \\
\hline LOA & 10 & meter \\
\hline B & 156 & tonne \\
\hline Gross tonnage & \multicolumn{2}{|c|}{ HFO } \\
\hline Fuel type & 313 & days \\
\hline Annual operation days & $1518 \times 2$ & $\mathrm{~kW}$ \\
\hline Engine power & &
\end{tabular}


289

290

291

292

\begin{tabular}{|c|c|c|}
\hline Life span & 30 & year \\
\hline
\end{tabular}

Table 2 Case study vessel operational profile

\begin{tabular}{|c|c|c|c|c|}
\hline Category & Sailing & Manoeuvring & Port & Unit \\
\hline Operation profile & 6 & 0.6 & 3 & hours \\
\hline Engine Load & $74 \%$ & $33 \%$ & 0 & percentage \\
\hline Power required & 2250 & 1000 & 0 & $\mathrm{~kW}$ \\
\hline SFOC & 191 & 214 & 0 & $\mathrm{~g} / \mathrm{kWh}$ \\
\hline
\end{tabular}

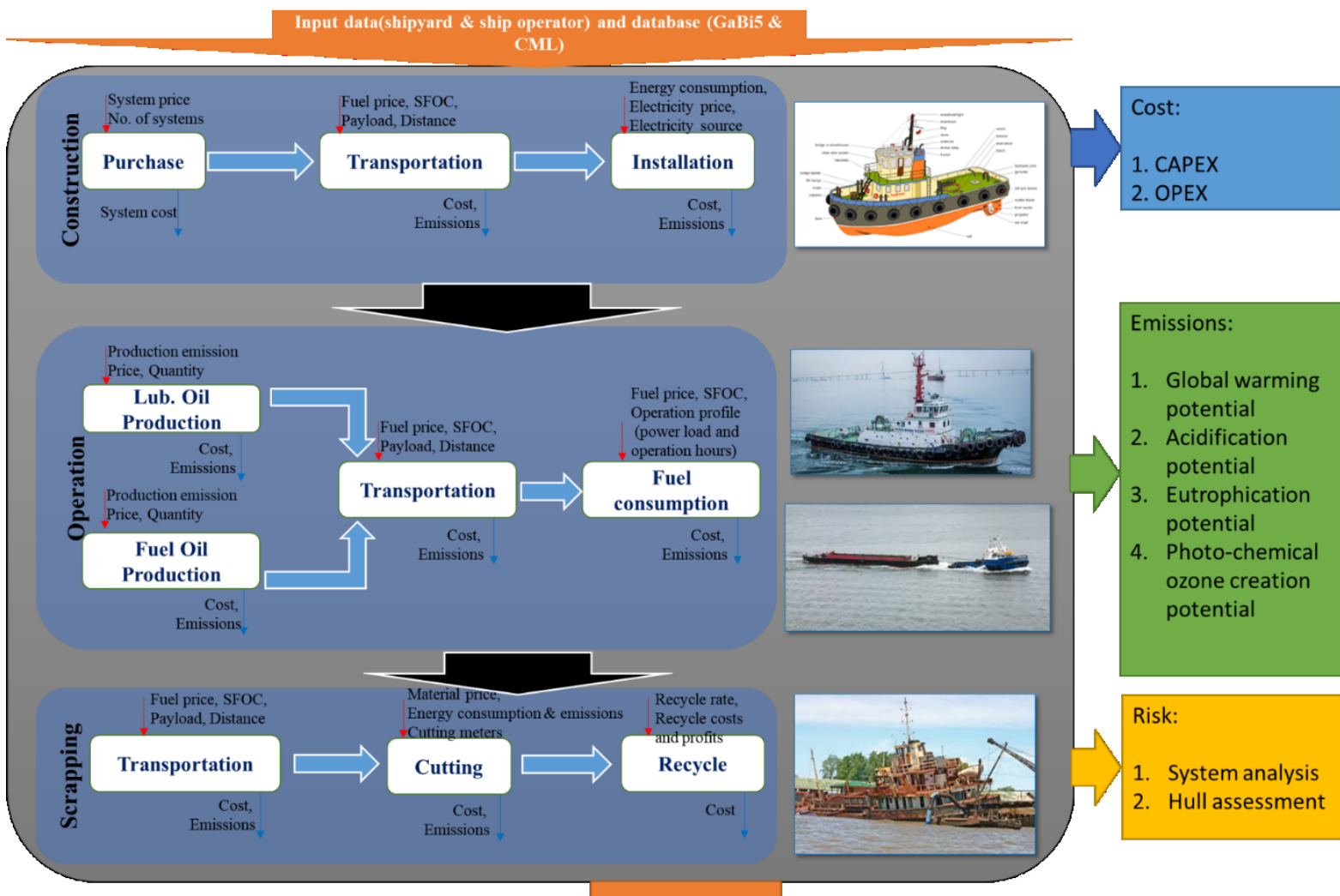

Life Cycle Cost Assessment Results (LCCA)

\&

Life Cycle Assessment Results (LCA)

Figure 4 Main engine related activities consideration and flow

\subsection{LifE CYCLE INVENTORY ANALYSIS}

\subsubsection{LCA model - commercial software GaBi}

Based on the aim and the scope established in the previous section, an LCA model was built and is presented in Figure 5. This figure includes the activities of the main engine from construction (purchase, transportation and installation), to operation phase (fuel consumption and transportation) and to scrapping of engine (disassembling, transportation, recovery etc.). 
300 The blue arrows represent the flow of engines; the fuel for ship operation is highlighted in red

301 colour and fuel for transportation is in black; green arrows show the supply of electricity.

302 With this model (includes ship particulars, operational profiles, etc.) and the application of $303 \mathrm{GaBi}$ software and database, the emissions inventory is set up and shown in Table 3. As two 304 environmental impact categories are considered in this study (GWP and AP), the emission 305 release breakdowns are presented in the table. It is apparent that the operation of the vessel 306 contributes the most of emission through the life span.

307 The way to estimate the emissions (apart from ship operation) is based on the database and 308 empirical equations from $\mathrm{GaBi}$ which estimates the material used and emissions generated for 309 many activities (not usually considered in ship industry), such as fuel oil production and 310 transportation.

\section{Propulsion system LCA (tug) \\ Process plan:Reference quantities \\ The names of the basic processes are shown.}

311

312

313

314

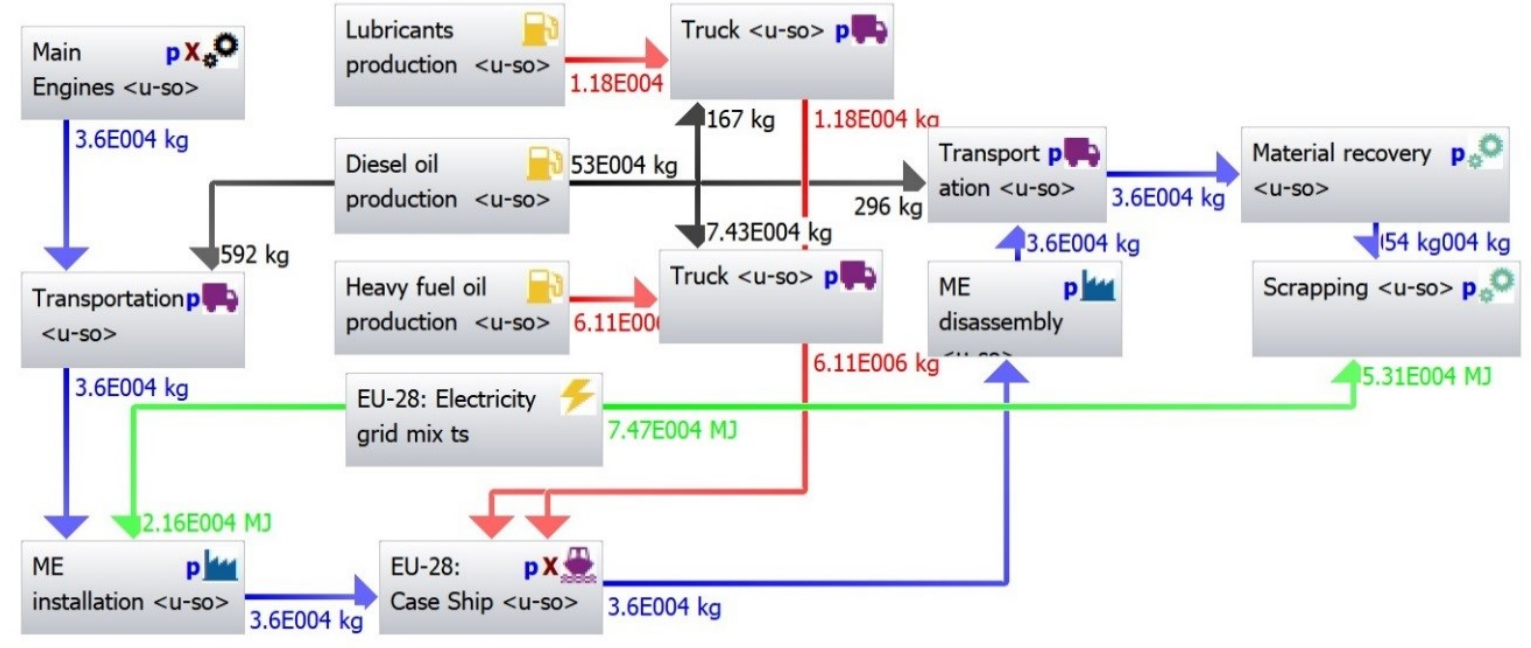

Figure $5 \mathrm{GaBi}$ LCA model of the case ship

Table 3 Emission inventory of life cycle assessment

\begin{tabular}{|c|c|c|}
\hline \multirow{2}{*}{ Module name } & \multicolumn{2}{|c|}{ Emission category } \\
\cline { 2 - 3 } & $\begin{array}{c}\text { Global Warming Potential } \\
\left(\mathrm{kg} \mathrm{CO}_{2} \text { eq. }\right.\end{array}$ & $\begin{array}{c}\text { Acidification Potential } \\
\left(\mathrm{kg} \mathrm{SO}_{2} \text { eq. }\right)\end{array}$ \\
\hline Transportation & $9.32 \times 10^{5}$ & $1.11 \times 10^{3}$ \\
\hline Heavy Fuel oil production & $1.14 \times 10^{7}$ & $4.94 \times 10^{4}$ \\
\hline Lubricating oil production & $9.14 \times 10^{4}$ & 393 \\
\hline Diesel oil production & $1.48 \times 10^{5}$ & 590 \\
\hline Tug ship operation & $7.92 \times 10^{7}$ & $2.70 \times 10^{6}$ \\
\hline Other activities & $1.24 \times 10^{4}$ & 23.2 \\
\hline Total & $9.17 \times 10^{7}$ & $2.76 \times 10^{6}$ \\
\hline
\end{tabular}


317 The ShipLCA software was developed to focus on the life cycle assessment of ships, machinery 318 system as well as other applications in the marine industry (Bharadwaj et al., 2016). The scope 319 of the software includes the construction, operation, maintenance and scrapping phase of the 320 ship life. In each phase, activities can be defined and considered to estimate the energy 321 consumption, emissions release and related costs (Jeong et al., 2018).

322 At present there is no life cycle software specific for the marine/ship building industry, and it 323 becomes very time consuming and difficult to carry out the whole life cycle assessment. The 324 ShipLCA software fills the gap on existing LCA software with the consideration of ship life stages and various activities. Within ShipLCA the three most significant impacts are included: cost, environment and risk (machinery systems), and the software can be used to help shipyards, ship owners and operators, and policy makers to estimate the life cycle impacts during the early design stage (Figure 6). The software will help to determine optimal alternatives while selecting engines, configuring systems or applying different sources of electricity; an example of ShipLCA result plot is shown in Figure 7 together with elements under consideration.

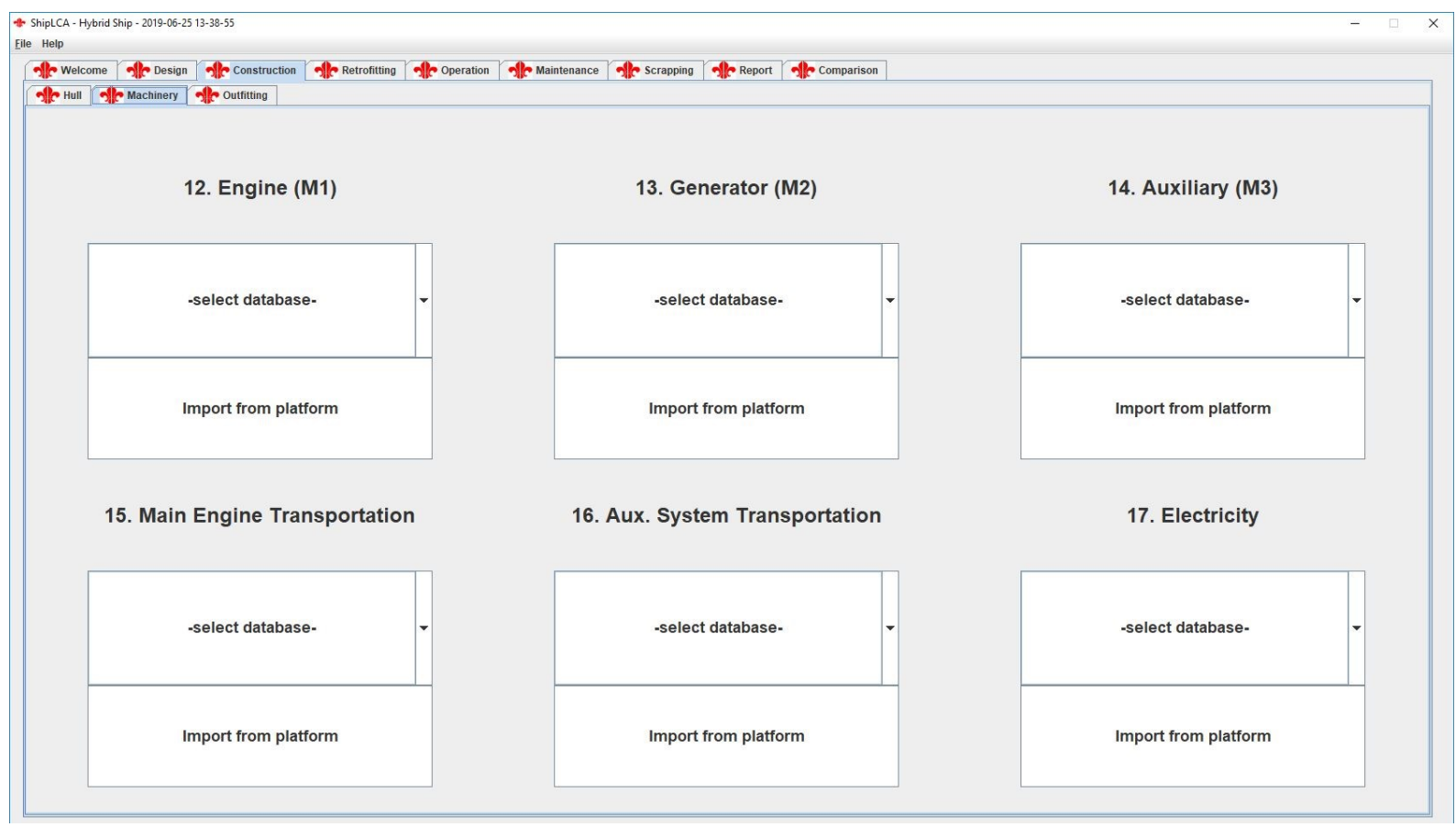




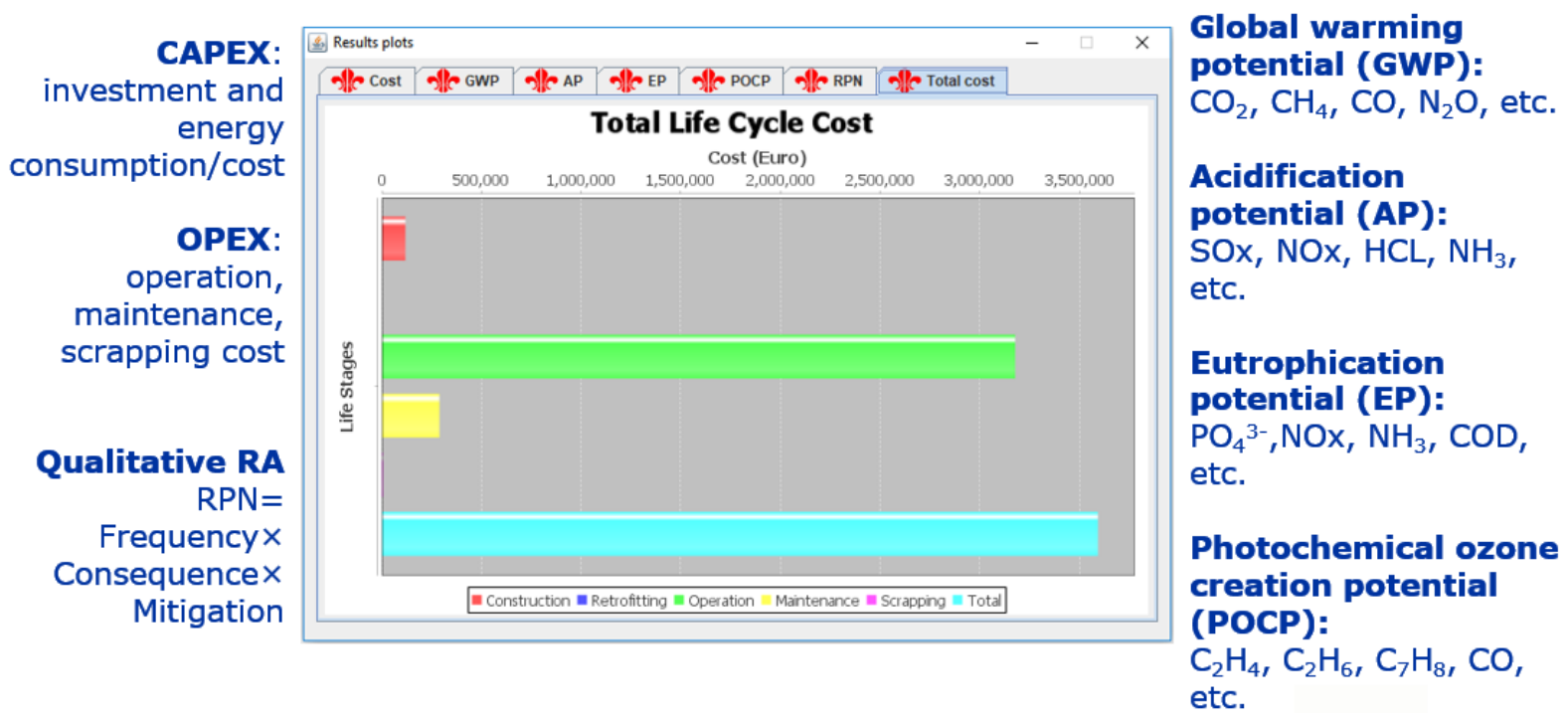

Figure 7 Example of software results and considered elements

The way to verify the results from ShipLCA software is following the procedures:

1. Setting up the same goal and scope for the case study;

Similarly to Section 4.1, the goal and scope of the tugboat assessment is to determine the environmental impact during the construction, operation, maintenance and scrapping phases of the vessel; among these phases cash flow, energy flow and emission flow will be considered; similarly some assumptions will be taken into account: a) only propulsion system under consideration; b) carbon factor is applied to estimate; c) some phases will be disregarded as irrelevant or minor impact; d) engine output variable follows the same relationship; e) $\mathrm{GaBi}$ database will be applied where no data available from shipyard or operators.

2. Modelling the case in ShipLCA software;

Similar to GaBi model, a model will be established in ShipLCA software following the specification of the vessel: a) ship in Table 1; b) operational profile in Table 2; c) available data from shipyard; d) data exploited from GaBi. Within ShipLCA software, all the activities and phases are pre-defined for the marine industry and this is the greatest different between ShipLCA and GaBi.

Data collection required for ShipLCA software covers the ship particulars, engine specification and operational profile; to be specific, the required and considered data are: ship geometry parameters, engine weights and maximum power output, cost and emissions related to transportation, cost and emissions related to electricity use, annual operation days, daily operation hours, power required and specific fuel oil consumption. The main equations involved are derived by the ones in GaBi but further details were added based on the requirements of ship building industry. 
For life cycle analysis, environmental impact is under investigation: mainly emission from fuel generation and consumption, electricity generation and transportation. The environmental impact categories under considerations are: Global warming potential $\left(\mathrm{CO}_{2}, \mathrm{CH}_{4}, \mathrm{CO}, \mathrm{N}_{2} \mathrm{O}\right.$, etc.), Acidification potential (SOx, $\mathrm{NOx}, \mathrm{HCL}, \mathrm{NH}_{3}$, etc.), Eutrophication potential $\left(\mathrm{PO}_{4}{ }^{3-}\right.$, $\mathrm{NOx}, \mathrm{NH}_{3}, \mathrm{COD}$, etc. $)$ and Photochemical ozone creation potential $\left(\mathrm{C}_{2} \mathrm{H}_{4}, \mathrm{C}_{2} \mathrm{H}_{6}, \mathrm{C}_{7} \mathrm{H}_{8}, \mathrm{CO}\right.$, etc.). The quantities of these emissions could be determined by collecting historical data and calculation. The emission databases from Gabi to predict the emission quantity are referred to for transportation, electricity generation and fuel generation. Regarding the fuel consumption related emissions, IMO's report is referred to (the same as the assumption in Section 3.1.).

The quantities of these emissions will be converted to different potential indicators to quantify the impact because different emission has different lifetime and ability to affect the environment. The different potential indicators are selected for different impacts for different characterisation methods in order to provide a final impact value through the lifetime of product or system. This paper will use CML 2001 method for characterisation; therefore, the indicators of GWP, AP, EP and POCP are $\mathrm{CO}_{2}, \mathrm{SO}_{2}, \mathrm{PO}_{4}{ }^{3-}$ and $\mathrm{C}_{2} \mathrm{H}_{4}$ respectively. These are selected because they have either the largest quantity or could cause most severe consequence or well known in the impact potential.

For the life cycle cost assessment, similar activities and life stages are considered. With the required costs collected from the relevant consultant websites, the overall cost can be determined, such as fuel cost, transportation cost, electricity cost and so on.

The risk assessment calculation follows the Formal Safety Assessment (FSA) (IMO, 2018b). The procedures are:

The ShipLCA software also includes a decision making process which converts all the impacts (environmental, economic and risk) into monetary terms for comparison. This will allow the comparison of different alternatives from the perspective of not only individual impact and life phase but also the holistic lifetime.

\section{Comparing the results between software;}

The results from GaBi mainly focus on environmental impacts and Table 4 shows the results from both software (ShipLCA and $\mathrm{GaBi}$ ). 
Table 4 Emission inventory: comparison between operation phase and the total lifetime

\begin{tabular}{|c|c|c|}
\hline \multirow{2}{*}{ Module name } & \multicolumn{2}{|c|}{ Emission category } \\
\cline { 2 - 3 } & \multicolumn{2}{|c|}{ Global Warming Potential $\left(\mathrm{kg} \mathrm{CO}_{2}\right.$ eq. $)$} \\
\cline { 2 - 3 } & ShipLCA & $\mathrm{GaBi}$ \\
\hline Operation phase & $9.40 \times 10^{7}$ & $9.06 \times 10^{7}$ \\
\hline Total & $9.73 \times 10^{7}$ & $9.17 \times 10^{7}$ \\
\hline
\end{tabular}

394

4. Determining the variation between results;

396 While verifying the model, the way to check whether the model is acceptable is by comparing

397 the results between the two models. As the models are setup based on different database, an

398 acceptable variation should be determined for variation.

399 5. Remodelling the case in ShipLCA to achieve an acceptable level of result variation;

400 If the variation is not in this range, the model will be modified, and the evaluation will be 401 conducted again. Since this case is more focusing on Global Warming Potential, it is obviously 402 the variations of GWPs are about $4 \%$ and $6 \%$ from the perspective of operational and life cycle 403 total results.

6. Determining a verified ShipLCA model for tugboat case.

\subsection{LIFE CYCLE IMPACT ANALYSIS}

406

407

408

409

410

411

412

413 In scenario 2, 3 medium engines replace 2 large engines. The engines are operated at $71 \%$

414 engine load (at sea) and 31\% (manoeuvring);

415

To test and analyse the impact of different engine configurations on the vessel performance, five scenarios are under assessment based on the model established and mentioned in the previous section. Five scenarios with Niigata engines (Niigata, 2019) are listed below:

a. Scenario 1 (original): two large engines running $-1518 \mathrm{~kW} \times 2$

The vessel as described in the inventory setup is used as the basis for the first scenario. The engines are operated at 74\% engine load (at sea) and 33\% (manoeuvring);

b. Scenario 2: three medium engines running $-1062 \mathrm{~kW} \times 3$

c. Scenario 3: two medium engines running $-1062 \mathrm{~kW} \times 2$ 
416 This scenario has the same engine type as Scenario 2 but there are only 2 medium engines

417 running other than 3. The engines are operated at $106 \%$ engine load (at sea) and $47 \%$ 418 (manoeuvring); under the sailing condition, the engines are overloaded. The operation concept 419 suggests this as infeasible already, but it is still under consideration to find out whether 420 emission released will be improved.

d. Scenario 4: four small engines running $-761 \mathrm{~kW} \times 4$

422 In scenario 4, 4 small engines are equipped on the vessel. The engines are operated at $74 \%$ 423 engine load (at sea) and 33\% (manoeuvring);

e. Scenario 5: three small engines running $-761 \mathrm{~kW} \times 3$

425 This scenario has the same type of engine as Scenario 4 but only 3 small engines are running. 426 The engines are operated at 99\% engine load (at sea) and 44\% (manoeuvring); under the sailing 427 condition, the engines are nearly fully loaded.

\subsubsection{GaBi LCA results}

429 With the help of the LCA model, the emission potentials are determined and shown in Figure 4308 and Figure 9. From the results, it can be seen that the vessel operation phase is still the largest 431 contributors under all scenarios. It is also reasonable to consider the reduction of emission/fuel 432 consumption during the operation phase to achieve better environmental protection.

433 Among the five scenarios, scenario 3 has the lowest emission for both GWP and AP: $8.93 \times 10^{7}$ $434 \mathrm{~kg} \mathrm{CO} 2$ eq. and $2.73 \times 10^{6} \mathrm{~kg} \mathrm{SO}_{2}$ eq.. Scenario 4 has the highest emission for both as well: $4359.36 \times 10^{7} \mathrm{~kg} \mathrm{CO}_{2}$ eq. and $2.77 \times 10^{6} \mathrm{~kg} \mathrm{SO}_{2}$ eq.. It is because the engines were operated under a 436 more efficient range of engine load which requires less fuel consumption when providing the 437 same power output. Furthermore, comparing the five scenarios, it is apparent that different 438 engine configurations will result in different emission release, and as such various 439 configurations should be assessed and compared from the aspects of environmental potential 440 in order to determine the optimal engine configuration for any new vessel. 


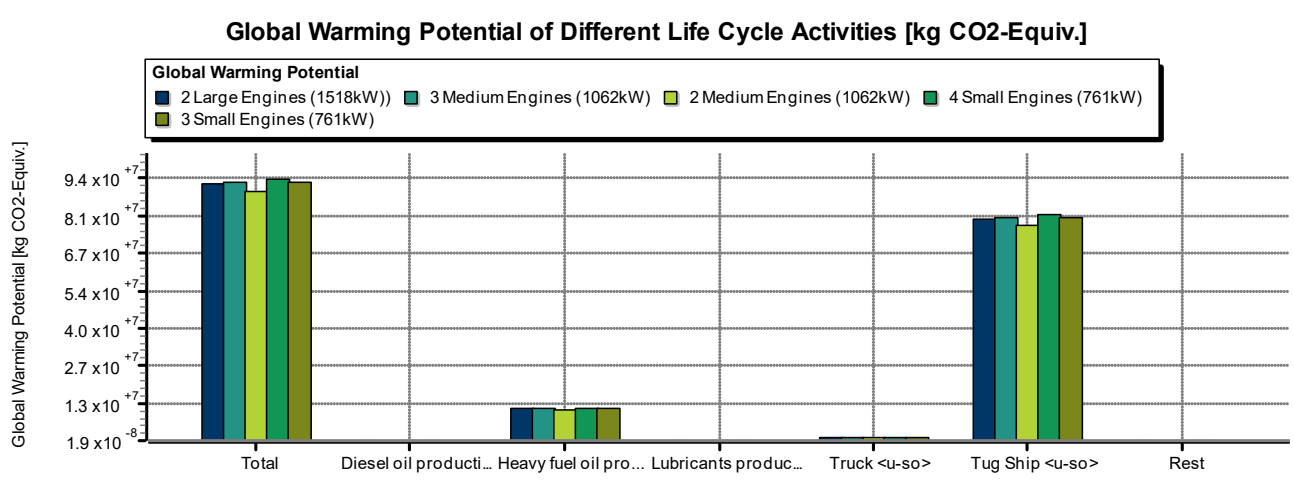

Figure 8 Global Warming Potential vs Life Cycle Activities [ $\mathrm{kg} \mathrm{CO}$ eq.]

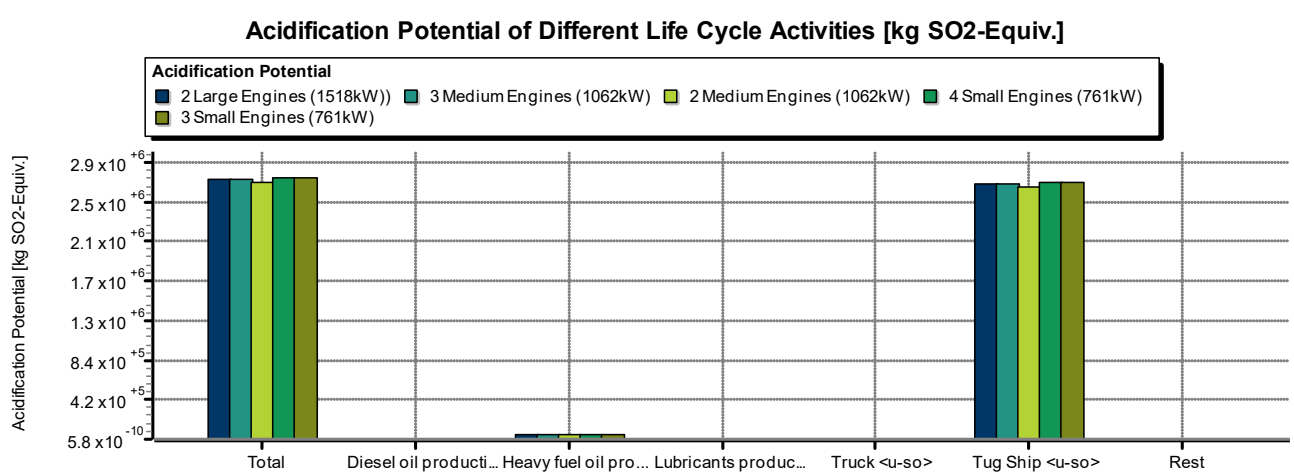

Figure 9 Acidification Potential vs Life Cycle Activities [kg $\mathrm{SO}_{2}$ eq.]

The fuel oil consumption for 30 years of operation was also determined through the LCA model and the results are presented in Table 5. It shows that applying the third configuration the overall fuel oil consumption is the lowest.

Table 5 Fuel oil consumption for five scenarios/configurations

\begin{tabular}{|c|c|c|c|c|c|}
\hline Scenario & 1 & 2 & 3 & 4 & 5 \\
\hline Fuel oil consumption (thousand tonne) & 25.36 & 25.61 & 24.68 & 25.89 & 25.56 \\
\hline
\end{tabular}

However, under the condition of scenario 3, the engines are operated under abnormal conditions as the overloaded by $6 \%$. It is not suggested to be run the engines under this operation condition which may increase risk and maintenance of the engines. Among five scenarios, there are three of them which have their engine running at normal conditions: scenario 1, 2 and 4. Among these three, the first configuration with two large engines has the best performance (lowest emission and fuel consumptions).

\subsubsection{ShipLCA results}


a) Life cycle analysis results

461 To estimate the environmental impact, the processes mentioned in Section 3.2.2 were applied.

462 The emission quantities were collected and calculated and then converted into the indicators.

463 The life cycle environmental impacts from ShipLCA are given in the following table.

464 Table 6 Life cycle inventory of original case: emission from different stages and categories

\begin{tabular}{|c|c|c|c|c|}
\hline Life stage & Construction & Operation & Scrapping & Total \\
\hline GWP (tonne $\mathrm{CO}_{2}$ eq.) & 3321.33 & 93944.16 & 2.82 & 97268.31 \\
\hline $\mathrm{AP}$ (tonne $\mathrm{SO}_{2}$ eq.) & 9.50 & 1325.49 & 0.00065 & 1334.99 \\
\hline $\mathrm{EP}$ (tonne $\mathrm{PO}_{4}{ }^{3-}$ eq.) & 0.86 & 172.78 & 0.00016 & 173.64 \\
\hline $\mathrm{POCP}$ (tonne $\mathrm{C}_{2} \mathrm{H}_{6}$ eq.) & 0.61 & 61.75 & 0.00010 & 62.36 \\
\hline
\end{tabular}

b) Risk assessment (Formal Safety Assessment (FSA))

With the application of FSA, the following hazards were identified and judgement on frequency and consequence are made. Then mitigation methods were investigated to prevent the hazard from happening or correct the hazard after happening. The total RPN number from the table is 84 and with an assumption of vessel price of $€ 12$ million, the estimated risk cost is $€ 1.01$ million.

Table 7 FSA risk assessment on engine operations for original case

\begin{tabular}{|c|c|c|c|}
\hline Risk hazards & Frequency & Consequence & Mitigation \\
\hline No.1 G/E fails & 2 & 2 & 1 \\
\hline No.2 G/E fails & 2 & 2 & 1 \\
\hline No.3 G/E fails & 2 & 2 & 1 \\
\hline No.1 Motor Fails during normal operation & 2 & 6 & 2 \\
\hline No.2 Motor Fails during normal operation & 2 & 6 & 2 \\
\hline No.1 DC Variable speed drive fails during operation & 1 & 6 & 2 \\
\hline No.2 DC Variable speed drive fails during operation & 1 & 6 & 2 \\
\hline
\end{tabular}

c) Life cycle cost analysis and total cost:

475 LCCA considers the following aspects: engine configurations, such as engine price, fuel price, 476 transportation fees, etc.. As the previous estimation of environmental impact and risk costs, the 477 life cycle total cost can be determined. The following table presents the costs from different 478 life stages and impacts.

Table 8 Cost assessments from the perspective of economy, environmental, risk and overall 480 level

\begin{tabular}{|c|c|c|c|c|}
\hline Life stages & Construction & Operation & Scrapping & Total cost \\
\hline Life cycle cost (Euro) & 104,058 & $13,924,544$ & 210,036 & $14,238,638$ \\
\hline Environmental converted cost (Euro) & 1,608 & $15,602,419$ & 73 & $15,604,099$ \\
\hline Risk coverted cost (Euro) & 0 & $1,008,000$ & 0 & $1,008,000$ \\
\hline Total life cycle cost (Euro) & 105,666 & $30,534,963$ & 210,109 & $30,850,737$ \\
\hline
\end{tabular}


483 Three reasonable cases are scenario 1, 2 and 4 which equip 2 large, 3 medium and 4 small engines on board. This section will compare the results from ShipLCA for these three scenarios to determine the optimal alternatives. The results are presented in Table 9:

Table 9 Cost, environmental and risk results for three reasonable scenarios

\begin{tabular}{|c|c|c|c|c|c|}
\hline \multirow{2}{*}{ Scenarios } & \multirow{2}{*}{ Cost } & \multicolumn{2}{|c|}{ Environmental } & \multirow{2}{*}{ Risk } & \multirow{2}{*}{ Total cost } \\
\cline { 3 - 4 } & & GWP & AP & & \\
\hline Scenario 1 & $14,238,638$ & 103,765 & 1,684 & 84 & $30,850,737$ \\
\hline Scenario 2 & $14,194,906$ & 103,403 & 1,678 & 84 & $30,752,468$ \\
\hline Scenario 4 & $14,264,951$ & 103,854 & 1,685 & 84 & $30,890,324$ \\
\hline Unit & $€$ & tonne $\mathrm{CO}_{2}$ eq. & tonne $\mathrm{SO}_{2}$ eq. & RPN & $€$ \\
\hline
\end{tabular}

487

488 When considering cost alone (no environmental or risk cost), the cost results are all around $489 € 14.2$ million for all scenarios. This is because the difference between them is the engine prices 490 due to different engine types. Risk level is the same for different cases as the total operating 491 hours and power output are the same.

492 When considering the environmental impact, the fuel consumption is estimated first and the 493 emissions release is then derived based on the amount of fuel consumed and emission factors, 494 such as carbon conversion factor, sulphur content and NOx emission curve from Section 3.2. 495 The results show that Scenario 2 has the lowest emissions released from the perspective of 496 GWP and AP potential. The emission credits for $\mathrm{CO}_{2}$ and $\mathrm{SO}_{2}$ used in the software are 24 and $7,788 €$ per tonne respectively (Maibach et al., 2007). With these values, the equivalent costs

498 for environmental impacts can be calculated and are $€ 2.48 \mathrm{E}+6$ and $€ 1.31 \mathrm{E}+7$. However, based 499 on the report from World Bank, the carbon credit was predicted to be $€ 36-72$ per tonne $\mathrm{CO}_{2}$ in 5002020 but according to IPCC, it would be increased to $€ 122-5,456$ in 2030 and 221-12,897 per 501 tonne $\mathrm{CO}_{2}$ e (Berg et al., 2019; Rogelj et al., 2018). The damage cost of SOx is estimated by EU to be $€ 10,900$ per tonne SOx in 2016 (European Commission, 2019). Therefore, the environmental impact will become more and more dominate as the emission credits growing rapidly. In this study, for the purpose of verification, same credit factors were adopted and since they were used in a linear function: Environmental impact $(€)=$ Emission quantity (tonne) $\mathrm{x}$ emission credits ( $€ /$ tonne), there will be no effect to the verification result. Since all the impact results can be expressed in monetary terms, an optimal solution can be obtained just by adding all values for each scenario. In this case, the results indicate that the configuration with

5093 medium size engines is the most cost effective and environmentally friendly among three scenarios.

\section{CONCLUSIONS AND FUTURE WORK}

512 This paper carried out an analysis on a tugboat's life cycle performance specifically estimating 513 and comparing different propulsion system configurations to select the optimal one with lowest 
emissions release, cost and hazard impacts. Five different engine configurations were selected and assessed with the help of life cycle assessment software, GaBi and ShipLCA, which holistically evaluates the select ship with varied configurations. The results indicate the optimal engine configuration is to equip the tugboat with three medium engines which generated emissions equivalent to the cost of 15.5 million euros, invested 14.2 million euros and has a risk impact equivalent to 1.01 million euros. This paper not only provides a case study for tugboat configuration assessment but also supports the life cycle assessment methodology as a general evaluation method for carbon emission reduction technologies to meet the extreme requirement of emissions control in the next few decades.

At present there is no life cycle software specific for the marine/ship building industry, and it becomes very time consuming and difficult to carry out the life cycle assessment. The ShipLCA software fills the gap on existing LCA software with the consideration of ship life stages and various activities. Within ShipLCA the three most significant impacts are included: cost, environment and risk, and the software can be used to help shipyards, ship owners and operators, and policymakers to estimate the life cycle impacts during the early design stage. The software will help to determine optimal alternatives while selecting engines, configuring systems or applying different sources of electricity.

According to the analysis and evaluation with a limited scope in this paper, we could conclude:

a. The operational phase contributes the most emission (about $85 \%$ of overall emissions) in the tug boat life span;

b. Changing the engine configuration has an impact on ship life cycle performances such as fuel consumption and emission release;

c. A life cycle assessment could be applied and will help to determine the impacts of different alternatives so that the optimal alternative could be obtained; this can be more accurate if holistic ship life and comprehensive activities are considered.

d. ShipLCA proved to be able to evaluate the ship life cycle impact by assessing the performances for the tug vessel and comparing with the commercial model;

There are still further work to improve the study:

a. The maintenance phase could be considered comprehensively to achieve a full LCA assessment; more details of manufacturing and scrapping phase will be helpful to achieve this full assessment;

b. More environmental categories and emission credits could be included; in this study, only four emission potentials categories and two emission credits are under considerations; 
c. The risk assessment is performed in a simplistic way; a quantitative risk assessment

\section{ACKNOWLEDGEMENT}

552

553

554

555

556

557

558

559

560

561

562

563

564

565

566

567

568

569

570

571

572

573

574

575

576

577

578

579

580

581

582

583

584

585 using historical data collected from ship operators will increase the content and accuracy of the overall assessment.

The authors gratefully acknowledge that the research presented in this paper was partially generated as part of the HORIZON 2020 SHIPLYS (Ship Life Cycle Software Solutions) Project, Grant agreement number 690770.

\section{REFERENCE}

Berg, T., Leuschner, P., Merusi, C., Klein, N., Trim, I., Ackva, J., Acworth, W., van Andel, E., Bartlett, N., Bedrosyan, D., Besley, D., de Bienassis, T., Black, S., Bourgeault, E., Brock, D., Burns, N., Burtraw, D., Garcia Cano, M., Castro Rodriguez, M., Zhibin, C., Crippa, M., Van Dender, K., Dhakhwa, T., Maria Dias, A., Dinakaran, C., Dressler, L., Elgouacem, A., Englert, D., Erb, T., Escalona, V., Escária, S., Ferreira, E., Flues, F., Forstorp, M., Gadde, H., de Gouvello, C., Gutu, S., Hallegatte, S., Heine, D., Huang, D., Kaiser, M., Churie Kallhauge, A., Khan, J., Kim, S., King, M., Han, L., Ying, L., Lopes, E., Marcus, V., Matsuki, T., Matsumura, W., Merrill, L., Mok, R., Oppermann, K., Pandey, S., Parry, I., Postic, S., Prasad, N., Putti, V., Rabe, B., Ramirez, J., Rana, Smita, Rana, Suneira, Rogers, S., Romero, G., Rose, S., Saldarriaga Arango, I., Sanchez, L., Santikarn, M., Shekhar Sinha, C., James Smith, J., Space, W., Srinivasan, S., Suda, K., Tao, N., Taylor, E., Teusch, J., Thioye, M., Toman, M., Ward, J., Zapfel, P., 2019. State and Trends of Carbon Pricing 2019. https://doi.org/10.1596/978-1-4648-1435-8

Bharadwaj, U.R., Koch, T., Milat, A., Herrera, L., Randall, G., Volbeda, C., Garbatov, Y., Hirdaris, S., Tsouvalis, N., Carneros, A., Zhou, P., Atanasova, I., 2016. Ship lifecycle software solutions (Shiplys) - an overview of the project, its first phase of development and challenges. Marit. Transp. Harvest. Sea Resour. 2, 889-896.

Blanco-Davis, E., del Castillo, F., Zhou, P., 2014. Fouling release coating application as an environmentally efficient retrofit: a case study of a ferry-type ship. Int. J. Life Cycle Assess. 19, 1705-1715. https://doi.org/10.1007/s11367-014-0780-8

Blanco-Davis, E., Zhou, P., 2014. LCA as a tool to aid in the selection of retrofitting alternatives. Ocean Eng. 77, 33-41. https://doi.org/10.1016/J.OCEANENG.2013.12.010

Bunkerworld, 2017. Available at: http://www.bunkerworld.com/prices/ (accessed 21th June 2017) [WWW Document].

CML, 2016. CML-IA Characterisation Factors - Leiden University [WWW Document]. Inst. Environ. Sci. URL https://www.universiteitleiden.nl/en/research/researchoutput/science/cml-ia-characterisation-factors (accessed 7.18.18).

Dedes, E.K., 2013. Investigation of Hybrid Systems for Diesel Powered Ships By. Soton 324.

European Commission, 2019. Handbook on the external costs of transport. https://doi.org/10.2832/27212 
Favi, C., Campi, F., Germani, M., Manieri, S., 2018. Using design information to create a data framework and tool for life cycle analysis of complex maritime vessels. J. Clean. Prod. 192, 887-905. https://doi.org/10.1016/j.jclepro.2018.04.263

GaBi, 2018. Software: GaBi Software [WWW Document]. URL http://www.gabisoftware.com/uk-ireland/software/ (accessed 7.18.18).

Gökalp, B., 2018. Exergy analysis and performance of a tug boat power generator using kerosene fuel blended with aspire methly ester. Fuel 229, 180-188. https://doi.org/10.1016/J.FUEL.2018.04.095

IMO, 2018a. INITIAL IMO STRATEGY ON REDUCTION OF GHG EMISSIONS FROM SHIPS Contents.

IMO, 2018b. REVISED GUIDELINES FOR FORMAL SAFETY ASSESSMENT (FSA) FOR USE IN THE IMO RULE-MAKING PROCESS.

ISO, 2006a. ISO 14040:2006 - Environmental management -- Life cycle assessment -Principles and framework [WWW Document]. Int. Organ. Stand. Geneva, Switz. URL https://www.iso.org/standard/37456.html (accessed 7.18.18).

ISO, 2006b. ISO 14044:2006 - Environmental management -- Life cycle assessment -Requirements and guidelines [WWW Document]. Int. Organ. Stand. Geneva, Switz. URL https://www.iso.org/standard/38498.html (accessed 7.18.18).

Jeong, B., Wang, H., Oguz, E., Zhou, P., 2018. An effective framework for life cycle and cost assessment for marine vessels aiming to select optimal propulsion systems. J. Clean. Prod. https://doi.org/10.1016/j.jclepro.2018.03.184

Koch, T., Blanco-Davis, E., Zhou, P., 2013. Analysis of Economic and Environmental Performance of Retrofits using Simulation.

Ling-Chin, J., Roskilly, A.P., 2016a. Investigating a conventional and retrofit power plant onboard a Roll-on/Roll-off cargo ship from a sustainability perspective - A life cycle assessment case study. Energy Convers. Manag. 117, 305-318. https://doi.org/10.1016/J.ENCONMAN.2016.03.032

Ling-Chin, J., Roskilly, A.P., 2016b. Investigating the implications of a new-build hybrid power system for Roll-on/Roll-off cargo ships from a sustainability perspective - A life cycle assessment case study. Appl. Energy 181, 416-434. https://doi.org/10.1016/J.APENERGY.2016.08.065

Ling-Chin, J., Roskilly, A.P., 2016c. A comparative life cycle assessment of marine power systems. Energy Convers. Manag. 127, 477-493. https://doi.org/10.1016/J.ENCONMAN.2016.09.012

Maibach, M., Schreyer, C., Sutter, D., Van Essen, H.P., Boon, B.H., Smokers, R., Schroten, A., Doll, C., Pawlowska, B., 2007. Handbook on Estimation of External Cost in the Transport Sector. Produced within the Study Internalisation Measures and Policies for All external Cost of Transport (IMPACT) version 1.0.

Niigata, 2019. Niigata Marine - Selection Guide.

Rahman, S.M.M., Handler, R.M., Mayer, A.L., 2016. Life cycle assessment of steel in the ship 
recycling industry in Bangladesh. J. Clean. Prod. 135, 963-971. https://doi.org/10.1016/j.jclepro.2016.07.014

Rogelj, J., Shindell, D., Jiang, K., Fifita, S., Forster, P., Ginzburg, V., Handa, C., Kheshgi, H., Kobayashi, S., Kriegler, E., Mundaca, L., Séférian, R., Ilariño, M.., 2018. Mitigation Pathways Compatible with $1.5^{\circ} \mathrm{C}$ in the Context of Sustainable Development. In: Global Warming of $1.5^{\circ} \mathrm{C}$. An IPCC Special Report on the impacts of global warming of $1.5^{\circ} \mathrm{C}$ above pre-industrial levels and related global greenhouse gas emission pathw. IPCC Spec. Rep. Glob. Warm. $1.5^{\circ} \mathrm{C} 82 \mathrm{pp}$.

Smith, T.W.P., Jalkanen, J.P., Anderson, B.A., Corbett, J.J., Faber, J., Hanayama, S., 2015. Third IMO GHG Study 2014: Executive Summary and Final Report. London, UK.

Wang, H., Oguz, E., Jeong, B., Zhou, P., 2019. Life cycle and economic assessment of a solar panel array applied to a short route ferry. J. Clean. Prod. https://doi.org/S095965261930513X

Yang, J., Chang, Y., Zhang, L., Hao, Y., Yan, Q., Wang, C., 2018. The life-cycle energy and environmental emissions of a typical offshore wind farm in China. J. Clean. Prod. 180, 316-324. https://doi.org/10.1016/j.jclepro.2018.01.082

Zhen, L., Wang, K., Wang, S., Qu, X., 2018. Tug scheduling for hinterland barge transport: A branch-and-price approach. Eur. J. Oper. Res. 265, 119-132. https://doi.org/10.1016/J.EJOR.2017.07.063

645

Zhu, J., Chen, L., Wang, B., Xia, L., 2018. Optimal design of a hybrid electric propulsive system for an anchor handling tug supply vessel. Appl. Energy 226, 423-436.

647 https://doi.org/10.1016/J.APENERGY.2018.05.131 